\title{
An Empirical Investigation of Learners' Decision to Resume an Online Degree Program
}

\author{
Zakaria I Saleh* \\ The American Intercontinental University (AIU), USA
}

\begin{abstract}
In is evident that the technology has become the key to a new world of education, where lectures are delivered and accessed without the time and distance boundaries. However, e-learning is more than just posting static or interactive material, or recording live sessions through the Learning Management Systems (LMS). While this may reduce cost and attract some learners, it may provide very little to some other learners. This study investigates the factors that could influence the online learner's attitudes towards resuming learning via the different models. There are many models of instructional design being used by different institution, and this research does not evaluate a specific model, and the LMS is used as a general concept. The study model was initially developed, which contained seven constructs, and a questionnaire was made up of the seven constructs, and distributed among online learners community. Using the responses of 387 learners, this research finds that all of the hypotheses are confirmed except for one. The decision to resume an online degree program found to be effected by the gained knowledge, the course content quality, and the use of suitable and proper course delivery medium (interactive material, audio, and presentations, recording live sessions). The data analysis indicates that the existence of suitable search options, the availability of appropriate relevant material, and a user friendly interface, are critical factors.
\end{abstract}

Keywords: E-learning; Learning management systems; Resuming e-learning; Gained knowledge; Intention to resume

\section{Introduction}

The Internet is expected to continue transforming human's everyday lives and education is no exemption. In fact, the Internet provided the means to eliminate all the obstacles that were standing the ways to deliver education at a distance, and E-learning was born. E-learning has become one of the most popular ways of gaining access to an education, especially to growing demand of an adult population that is trying to go back to school. The use of technology to facilitate learning is becoming accepted across educational institutions, and therefore, e-learning has grown to become one of the significant developments in markets with a variety of content delivery methods and tools. However, while the focus is largely on getting the infrastructure and creating the e-learning content, it is necessary to consider the individual factors that play an important role in the enrolment and going through a complete e-learning program of study. Fundamentally, e-learning is based on adult learning principles, learning styles, and instructional design. There exist a large number of studies on the acceptance of e-learning, but this study sets out an empirical research for investigating the element of e-learning in terms of method of educational principles, and evaluate factors affect the decision to resume enrollment in a program (learner retention) and identify potential dropouts. This study believes that the acceptance of technology while plays a role in the decision to accept an e-learning, but there exist an equal or maybe a more important acceptance element of e-learning, which involves the individual users' acceptance of e-learning in terms of method of educational principles. Therefore, this study aims to evaluate the factors that affect learner's acceptance and adaption of the electronic multimedia learning mechanism, as well as the factors affect the decision to resume enrollment in a program (learner retention). There are many factors potentially influencing E-learning effectiveness, such as media characteristics, learning context, technology, and learner characteristics [1]. It is expected that this research provides a roadmap to a better understanding of the success factors contributing to retaining a student that is already enrolled in an e-learning program, and outline the outcomes of the study to be the qualifications for potentially retaining online learners and provide it as a recommendation for the developers as a base for a better organizational e-learning system that meets the needs and demands of the learners.

\section{Electronic Learning Overview}

Electronic learning or E-learning (also known as online education) is a general term used to refer to computer-based learning, which deals with the technologies and the associated methodologies, where the learning takes place at a remote location, and involves the delivery of education from one location to another using networked and/or multimedia technologies. The explosion of technology has also made teaching outside the traditional classroom possible for teachers and has also provided learners with easy access to course material [2]. E-learning methods are generally categorized as asynchronous or synchronous. Asynchronous learning is when the participants are engage in the exchange of ideas or information without the involvement of other participants in real time (e.g. time discussion boards). Synchronous activities involve the exchange of information with one or more participants in real time (e.g. live chats). In asynchronous online courses, learners proceed at their own pace, if they need to listen to a lecture a second time, or think about a question for a while, they may do so without fearing that they will hold back the rest of the class [3].

E-learning has become an increasingly popular learning approach in higher education institutions due to the rapid growth of Internet technologies, where educational institutions are increasingly trying to

*Corresponding author: Zakaria I Saleh, The American Intercontinental University (AIU), USA, Tel: +18777013800; E-mail: DrZaatreh@AIM.com

Received December 06, 2017; Accepted December 29, 2017; Published January 02, 2018

Citation: Saleh ZI (2018) An Empirical Investigation of Learners' Decision to Resume an Online Degree Program . Arts Social Sci J 9: 323. doi: 10.4172/21516200.1000323

Copyright: (c) 2018 Saleh ZI. This is an open-access article distributed under the terms of the Creative Commons Attribution License, which permits unrestricted use, distribution, and reproduction in any medium, provided the original author and source are credited. 
use a greater variety of technologies in their learning and development programs. Therefore, identifying influential factors on technology acceptance was deemed important and focal for both researchers and practitioners [4]. For this reason, the authors were interested in identifying and studying the variables that influence technology acceptance in teaching delivery. Many studies investigated the technology acceptance model (TAM) for different related tasks with the e-learning, and used TAM as a basis for hypothesizing the effects of such variables on the use of e-learning as the application [5-19]. TAM proposes that perceived ease of use and perceived usefulness predict applications usage. In turn, perceived ease of use has been found to have a significant effect on perceived usefulness, and positive relationship has been found to exist between perceived usefulness and behavioral intention to use $[20,21]$. While e-learning has been integrated in many university programs, and is one of the new learning trends, however, e-learning is not a technology; it is rather a method of educational principles of effective multimedia learning using electronic educational technology [22], which provides new opportunities for interaction and communication between learners and instructor. E-learning is not just a change of technology. It is part of a redefinition of how people transmit knowledge, skills, and values to younger generations of workers and learners [23].

Key advantages of E-learning are flexibility, convenience and the ability to work at any place where an internet connection is available and at one's own pace, and ease of access to a great amount of information [24]. Other advantages of E-learning are the ability to communicate with fellow classmates independent of location or distance, with more variety in learning experience with the use of multimedia. E-classes are asynchronous which allows learners to participate and complete coursework in accordance with their daily commitments over the internet at different times. This makes an E-learning education a viable option for those that have other commitments such as family or work, and enables a higher degree of interactivity among professors and learners and easier study material coverage in both undergraduate and graduate learners [25]. In addition, there are also transportation cost (and time) benefits with not having to commute to and from campus. Disadvantages of E-learning include the lack of face-to-face interaction with a teacher and the feeling of isolation experienced by distance learning learners is also often cited, where most people cannot imagine a "classroom without walls", nor a completely different way of studying [25]. Compared to traditional education, e-learning also has no set times for classes and no assign physical place to meet in, which a represents a challenge to some of the learners who may not be well discipline, or can't managed time in a reasonable manner, who would become unable to cope with the work. The problem may arise when the learners technological capabilities or training might not be enough to do what's expected [2]. Another disadvantage the e-learning may have is that web and software development can be expensive, and the development of adaptive materials is also much more time-consuming than that of non-adaptive ones.

\section{Research Methodology}

This research will use the quantitative method and the generation of model and hypotheses as well as the development of instruments. What constitutes a quantitative research method involves a numeric or statistical approach to research design and can be used in response to relational questions of variables within the research [26]. The methods for measurement will be based on the statistical analysis of data collected through a questionnaire. A questionnaire was used as an instrument to collect the quantitative data in investigating the factors affecting learner's attitudes towards their eLearning enrolment and complete their program of study. To verify the hypotheses of the study, closed-ended questions were prepared based on the Likert scale containing an odd number of options labeled 1 to 5 , where 1 is labeled as the most positive end 5 is labeled as the most negative one with the label of "neutral" in the middle of the scale for 3. The questionnaire consisted of six constructs, namely Content Format Suitability (PFS), Perceived Content Quality (PCQ), Gained Knowledge (GK), Course Delivery Medium (CDM), Perceived Ease of Use (PEU), and Intention to Resume (IR).

\section{Instrument Construct Reliability and Validity}

The study model was initially developed, which contained seven constructs, and the questionnaire was generated and made up of the seven constructs. Construct validation is a procedure designed to help quantify the validity and quality of the items within the instrument and provide a summary index of whether the measure correlates positively, negatively, or not at all with a series of other measures, as well as the relative magnitude of those correlations, and provide confidence intervals for that match, taking into account the likelihood that some of the validating variables may not be independent of one another, therefore the measurement tool must fully represent the constructs intended for inclusion in their research [27]. Distribution of the questionnaire items across the constructs is illustrated in Tables 1 and 2.

To investigate the internal structure of instrument, the instrument's construct validity was confirmed through factor analysis after conducting a pilot test, and then to ensure that all variables have high loadings on only one factor some rearrangements were made, and then the study instrument in its final form. The assessment was based on Cronbach's Alpha. Since it was an early stage of research on hypothesized measures of a construct, the minimum level of reliability was set around 0.70 in the study. The inter-item correlation and the effects of deleting items on Alpha were used to determine the candidate items for further studies. Table 2 illustrates the Factor Loading of the instrument and explains the variance for all variables. Internal consistency among the items was also estimated using Cronbach's alpha coefficient, which depends on the concept of internal links between items. The values pertaining to the reliability of internal consistency using the Cronbach's alpha coefficient for all constructs, ranged between 0.722 and 0.913 and all exceeded the recommended value of 0.70 as acceptable for the Cronbach alpha coefficient.

\section{Study Hypotheses and Research Model}

This section represents the research model (Figure 1) which was based on the following hypotheses have been projected for the achievement of the aims and objectives of the study:

H1: Content format suitability is positively associated with the Perceived content quality.

$\mathrm{H} 2$ : Course content quality is positively associated with the gained knowledge via e-learning.

\begin{tabular}{|l|c|c|c|}
\hline Construct & Total items & P value & $\begin{array}{c}\text { Cronbach's } \\
\text { alpha }\end{array}$ \\
\hline Content Format Suitability & 6 & $<0.001$ & 0.837 \\
\hline Perceived Content Quality & 5 & $<0.001$ & 0.894 \\
\hline Gained Knowledge (GK) & 6 & $<0.001$ & 0.846 \\
\hline Course Delivery Medium & 4 & $<0.001$ & 0.924 \\
\hline Perceived Ease of Use (PEU) & 4 & $<0.001$ & 0.919 \\
\hline Intention to Resume (IR) & 5 & $<0.001$ & 0.848 \\
\hline
\end{tabular}

Table 1: Distribution of the questionnaire items across the constructs. 


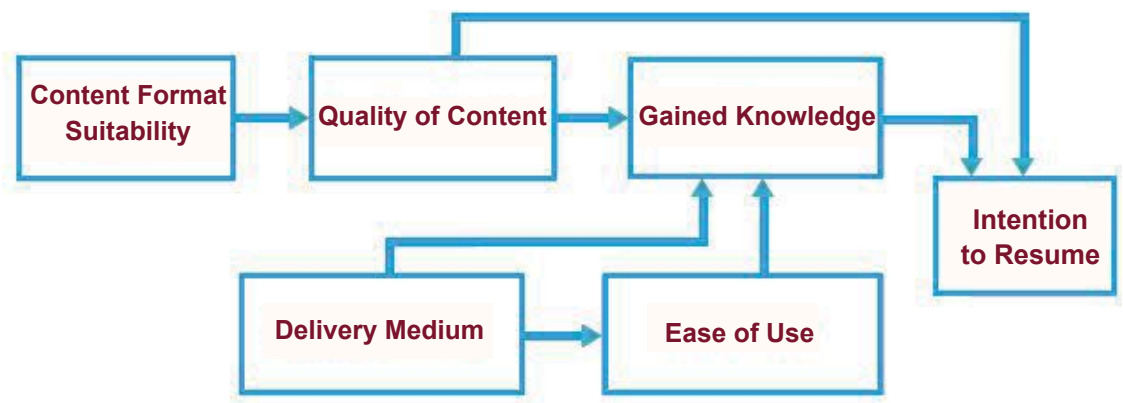

Figure 1: The research model.

\begin{tabular}{|c|c|c|c|c|c|c|}
\hline & Factor & Factor & Factor & Factor & Factor & Factor \\
\hline Q1 & 0.725 & & & & & \\
\hline Q2 & 0.764 & & & & & \\
\hline Q3 & 0.734 & & & & & \\
\hline Q4 & 0.693 & & & & & \\
\hline Q5 & 0.658 & & & & & \\
\hline Q6 & 0.784 & & & & & \\
\hline Q7 & & 0.818 & & & & \\
\hline Q8 & & 0.842 & & & & \\
\hline Q9 & & 0.874 & & & & \\
\hline Q10 & & 0.801 & & & & \\
\hline Q11 & & 0.78 & & & & \\
\hline Q12 & & & 0.659 & & & \\
\hline Q13 & & & 0.818 & & & \\
\hline Q14 & & & 0.85 & & & \\
\hline Q15 & & & 0.855 & & & \\
\hline Q16 & & & 0.867 & & & \\
\hline Q17 & & & 0.705 & & & \\
\hline Q18 & & & & 0.752 & & \\
\hline Q19 & & & & 0.885 & & \\
\hline Q20 & & & & 0.872 & & \\
\hline Q21 & & & & 0.795 & & \\
\hline Q22 & & & & & 0.803 & \\
\hline Q23 & & & & & 0.838 & \\
\hline Q24 & & & & & 0.781 & \\
\hline Q25 & & & & & 0.677 & \\
\hline Q26 & & & & & & 0.896 \\
\hline Q27 & & & & & & 0.902 \\
\hline Q28 & & & & & & 0.915 \\
\hline Q29 & & & & & & 0.904 \\
\hline Q30 & & & & & & 0.784 \\
\hline
\end{tabular}

Table 2: Factor loading of the Instrument.

H3: Course delivery medium positively influences the gained knowledge via e-learning.

H4: Course delivery medium is positively associated with the perceived ease of use.

H5: Perceived ease of use will have a positive effect on learners Gained Knowledge.

H6: Gained Knowledge has a positive influence on learner's intention to resume e-learning.

H7: Course content quality has a positive influence on learner's intention to resume e-learning.

In Figure 1, this model, "intention to Resume" is employed as a

\begin{tabular}{|l|l|c|c|}
\hline Demographic & & Frequency & Percentage \\
\hline Gender & Male & 163 & $42.12 \%$ \\
\hline \multirow{3}{*}{ Age } & Female & 224 & $57.88 \%$ \\
\hline \multirow{5}{*}{ Program Study level } & $<20$ years & 11 & $2.84 \%$ \\
\cline { 2 - 4 } & $21-30$ years & 206 & $53.23 \%$ \\
\cline { 2 - 4 } & $31-40$ years & 122 & $31.52 \%$ \\
\cline { 2 - 4 } & $41-50$ years & 36 & $9.30 \%$ \\
\cline { 2 - 4 } & $>50$ years & 12 & $3.10 \%$ \\
\cline { 2 - 4 } & Master Degree & 81 & $20.93 \%$ \\
\cline { 2 - 4 } & Bachelor & 242 & $62.53 \%$ \\
\cline { 2 - 4 } & Diploma & 64 & $16.54 \%$ \\
\hline
\end{tabular}

Table 3: Profile of the respondents.

predictor of future intention to continue their program of study via E-learning. The "ease of use" concept of the model is taking directly from the TAM with minor rephrasing to make it applicable to e-learning. In agreement with the literature, the model assumes that ease of use will mediate the influence of respectively "content format", the "quality of content" on "intention to resume". The quality of the information content of the learning material should indeed lead to the suitability of the "delivery medium" and therefore have a direct effect on the gaining the intended knowledge "gained knowledge", and therefore, impact he intention to resume the program of study (via e-learning). On the other hand, the quality of the system itself (e.g. technical stability and reliability, sufficient search and navigational functionalities, attractiveness of the user interface) is supposed to lead to a system that is easy to use, which again is assumed to contribute to the Gained Knowledge and an increased intention to resume the program of study. In order to investigate whether the mediation effects are partial or full, a direct relationship is added between Quality of Content and intention to o resume the program of study (Table 3).

\section{Data Collection}

An online survey was conducted to test the research model and evaluate the projected hypotheses. A convenience sampling method was used, since it is difficult to identify online enrolled learners. An email list 12,500 email accounts of college students was obtained from a US provider of mailing lists, and based on the university name; only 1321 emails were identified as online students. An email was sent to those students explaining the importance of the study and asking them to complete the survey (about 92 emails were bounced back undelivered). At the end of data collection period, only 387 surveys were completed, which should be sufficient for the study. Table 3 illustrates the profile of the study's respondents. 


\section{Hypotheses Testing}

H1: Format suitability is positively associated with the perceived content quality

In the statistical analyses of the data, an alpha of 0.05 is used as the cutoff for significance, and when the p-value is found to be less than 0.05 , then the null hypothesis is we reject, because there's no difference between the means and therefore, a significant difference does exist. Data analysis for this hypothesis indicates that the Pearson correlation coefficient between the format suitability and the perceived content quality is 0.08 , which indicates a very weak positive correlation. The $\mathrm{P}$-value in testing the zero correlation is calculated as 0.27 , which means the correlation is not statistically significant. So, the results suggest that the predictive value of the benefit of using the suitable format does not directly affect the perceived content quality, and thus, can't be used to predict the perceived course content quality.

H2: Course content quality is positively associated with the gained knowledge via e-learning

Based on the data analysis, as shown in Table 4, there is a statistically significant positive effect of course content quality on the gained knowledge via e-learning, where the estimated path coefficient value to be $\beta=0.278$. This is statistically significant at the level $p<0.001$. This result indicates a direct effect of course content quality on the gained knowledge. For further confirmation in identifying the effect of course content quality on the gained knowledge via e-learning, the predicted value of the gained knowledge of using a LMS was verified using linear regression analysis $\left(\mathrm{R}=0.7647\right.$ and $\left.\mathrm{R}^{2}=0.5847\right)$, and by considering course content quality as a predictor (the independent variable, the gained knowledge of LMS (the dependent variable) can be predicted from this result. Therefore, the second hypothesis was accepted.

H3: Course delivery medium positively influences the gained knowledge via e-learning

The data analysis results, as shown in Table 5, indicate the existing significant positive effect of the Course delivery medium on the gained knowledge via e-learning. The results show that the estimated coefficient value to be $\beta=0.338$, which is statistically significant at $p<0.001$, and this means that course delivery medium directly affects the knowledge gained through the LMS. Further linear regression analysis was carried out for this hypothesis for further validation in identifying the effect of course delivery medium on the gained knowledge and the predicted value of the knowledge gained through the LMS was verified using linear regression analysis $\left(\mathrm{R}=0.8733\right.$ and $\left.\mathrm{R}^{2}=0.7626\right)$., by considering the course delivery medium as a predictor (the independent variable), where it can predict the gained knowledge (the dependent variable). Thus, the third hypothesis was accepted.

\begin{tabular}{|l|c|c|c|c|}
\hline & $\begin{array}{c}\text { Observation } \\
\text { number }\end{array}$ & Median & Mean & St. Dev \\
\hline Course content quality & 387 & 3.71 & 3.76 & 0.6 \\
\hline Gained knowledge & 387 & 2.64 & 3.11 & 1.01 \\
\hline
\end{tabular}

Table 4: Statistics of course content quality and gained knowledge.

\begin{tabular}{|l|c|c|c|c|}
\hline & $\begin{array}{c}\text { Observation } \\
\text { number }\end{array}$ & Median & Mean & St. Dev \\
\hline Course content quality & 387 & 3.92 & 326 & 1.2 \\
\hline Gained knowledge & 387 & 2.64 & 3.11 & 1.01 \\
\hline
\end{tabular}

Table 5: Statistics of course delivery medium and gained knowledge.
H4: Course delivery medium is positively associated with the perceived ease of use

As shown in Table 6, the data analysis result indicates a statistically significant positive effect of the course delivery medium on the perceived ease of use of the LMS. The results show that the estimated coefficient value to be $\beta=0.396$, representing an indication of the path analysis coefficient, which is statistically significant at the level $\mathrm{p}<0.001$. This result points to the direct effect of course delivery medium on the perceived ease of use of the LMS. For further confirmation in identifying the effect of course delivery medium on the perceived ease of use of the LMS, the predicted value of the perceived ease of use of the LMS was verified using linear Regression Analysis $(\mathrm{R}=0.8093$ and $\mathrm{R}^{2}=0.7626$ ), by considering course delivery medium as a predictor (the independent variable), whereby we can predict the usefulness of LMS (the dependent variable). Thus, the fourth hypothesis was accepted.

H5: Perceived ease of use will have a positive effect on learners gained knowledge

Looking at Table 7, the data analysis for this hypothesis indicates a statistically significant positive effect of perceived ease of use on the gained knowledge using the LMS. The results indicate that the estimated coefficient value to be $\beta=0.454$, representing an indication of the path analysis coefficient, which is statistically significant at the level $\mathrm{p}<0.001$, thus indicating an increase in the value of the direct effect of perceived ease of use on gained knowledge when using the LMS. For further confirmation in identifying the effect of perceived ease of use on gained knowledge using the LMS, the predicted value was verified using linear regression analysis $\left(R=0.8457\right.$ and $\left.R^{2}=0.7152\right)$, by considering perceived ease of use (the independent variable), whereby we can predict gained knowledge using LMS (the dependent variable). Thus, the fifth hypothesis was accepted.

H6: Gained knowledge has a positive influence on learner's intention to resume e-learning

Looking at Table 8 , the data analysis revealed that gained knowledge has a significant positive effect on intention to resume e-learning through the LMS. The results indicate that the estimated coefficient value to be $\beta=0.334$, which is statistically significant at the level $\mathrm{p}<0.001$. This indicates the direct effect of the gained knowledge using the LMS on intention to resume the e-learning program. For further confirmation on identifying the effect of the gained knowledge through the LMS on learners intention and to obtain the predicted value for intention to resume e-learning using the LMS, linear regression analysis

\begin{tabular}{|l|c|c|c|c|}
\hline & $\begin{array}{c}\text { Observation } \\
\text { number }\end{array}$ & Median & Mean & St. Dev \\
\hline Course delivery medium & 387 & 3.92 & 326 & 1.2 \\
\hline Perceived ease of use & 387 & 4.21 & 3.39 & 1.26 \\
\hline
\end{tabular}

Table 6: Statistics of course delivery medium and the perceived ease of use.

\begin{tabular}{|l|c|c|c|c|}
\hline & $\begin{array}{c}\text { Observation } \\
\text { number }\end{array}$ & Median & Mean & St. Dev \\
\hline Perceived ease of use & 387 & 4.21 & 3.39 & 1.26 \\
\hline Gained knowledge & 387 & 2.64 & 3.11 & 1.01 \\
\hline
\end{tabular}

Table 7: Statistics of perceived ease of use and learners gained knowledge.

\begin{tabular}{|l|c|c|c|c|}
\hline & $\begin{array}{c}\text { Observation } \\
\text { number }\end{array}$ & Median & Mean & St. Dev \\
\hline Gained knowledge & 387 & 2.64 & 3.11 & 1.01 \\
\hline Intention to Resume & 387 & 4.07 & 3.72 & 1.21 \\
\hline
\end{tabular}

Table 8: Statistics of gained knowledge and learners' intention to resume e-learning 


\begin{tabular}{|l|c|c|c|c|}
\hline & $\begin{array}{c}\text { Observation } \\
\text { number }\end{array}$ & Median & Mean & St. Dev \\
\hline Perceived content quality & 387 & 3.71 & 3.76 & 0.6 \\
\hline Intention to Resume & 387 & 4.07 & 3.72 & 1.21 \\
\hline
\end{tabular}

Table 9: Statistics of course content quality and learners intention to resume e-learning.

was applied ( $\mathrm{R}=0.8226$ and $\left.\mathrm{R}^{2}=0.6766\right)$, by considering the gained knowledge as a predictor (the independent variable), whereby we can predict the intention to resume e-learning using LMS (the dependent variable). Thus, the sixth hypothesis was accepted.

H7: Course content quality has a positive influence on learner's intention to resume e-learning

Table 9, presents the data analysis and indicates that course content quality has a significant positive effect on the intention to resume e-learning through the LMS. The results indicate that the estimated coefficient value to be $\beta=0.412$, which is statistically significant at the level $\mathrm{p}<0.001$. This indicates the direct effect of the course content quality on learner's intention to resume the e-learning program. For further confirmation on identifying the effect of the course content quality on learners' intention and to obtain the predicted value for intention to resume e-learning using the LMS, linear regression analysis was applied $\left(\mathrm{R}=0.8682\right.$ and $\left.\mathrm{R}^{2}=0.7538\right)$, by considering the course content quality as a predictor (the independent variable), whereby we can predict the intention to resume e-learning using LMS (the dependent variable). Thus, the seventh hypothesis was accepted.

\section{Conclusion}

Now a day, getting an education is a very important because it is used to reduce most of the challenges faced in the modern life. The knowledge that is achieved through education becomes the key needed to open doors to a lot of opportunities and a better options as well as career growth. However, it is clear that the decision to pursue education through e-learning has to be well planned. Research findings in a related research that it is harder to retain learners in online courses than in traditional face-to-face courses. Learner dropout rate for online undergraduates ranges from $20 \%$ to $50 \%$, which is $10 \%$ to $20 \%$ higher than traditional classroom environments [28,29], where high drop-out rate in online classes has negative effect on both learners and academic institutions [29-31].

This paper examined the factors affecting learner retention and persistence in online education environment, but has only showed a limited view of a complex subject matter. It was found that before making a decision to resume their e-learning programs, the learners are evaluating ease of use of the LMS as well as the quality of the learning material, and then balance out all advantages and disadvantages, gained knowledge and choose to whether or not to resume enrollment in the program, once confirming the it meets the needs, the expectations, and own competence. It is clear that e-learning requires more than providing the technical means to access and recording live sessions through LMS. While this may reduce cost and attract some learners, it may provide very little to some other learners, and may mean a one-way communication if consideration is not made by the teaching institution to look bound the technology and meet the learner's expectations and needs. Provisions are to be made to connect the learning material to what the learners already know, and make e-learning a problem solver for the learners.

\section{References}

1. Ali AS (2015) The future of e-learning and tools in higher education. International
Journal of Advances in Computer Science and Technology 4: 1-5

2. Allen IE, Seaman J (2013) Changing course: Ten years of tracking online education in the United States. Babson Survey Research Group and Quahog Research Group

3. Arkorful V, Abaidoo N (2014) The role of e-learning the advantages and disadvantages of its adoption in Higher Education. International Journal of Education and Research 2: 397-410.

4. Cakir R, Solak E (2014) Exploring The Factors Influencing E-Learning Of Turkish EFI Learners Through TAM TOJET: The Turkish Online Journal of Educational Technology 13: 79-87.

5. Farahat T (2012) Applying the Technology Acceptance Model to Online Learning in the Egyptian Universities ETC 2012: International Educational Technology Conference 95-104.

6. Goyal S (2012) E-Learning: Future of Education Journal of Education and Learning 6: 239-242.

7. Horton W (2011) E-Learning by Design 2nd Edition John Wiley \& Sons Inc New Jersey.

8. Hsiao $\mathrm{CH}$, Yang $\mathrm{C}$ (2011) The intellectual development of the technology acceptance model: A co-citation analysis. International Journal of Information Management 3: 128-136.

9. Husseina $Z$ (2017) Leading to Intention: The Role of Attitude in Relation to Technology Acceptance Model in E-Learning IEEE International Symposium on Robotics and Intelligent Sensors pp: 159-164

10. Joo J, Sang Y (2013) Exploring Koreans smartphone usage: An integrated model of the technology acceptance model and uses and gratifications theory. Computers in Human Behavior 29: 2512-2518.

11. Khee CM, Wei Wei G, Jamaluddin SA (2013) Learners Perception towards Lecture Capture based on the Technology. Acceptance Model Procedia Social and Behavioral Sciences 123: 461-469.

12. Lee DY, Lehto MR (2013) User acceptance of YouTube for procedural learning: An extension of the technology acceptance model. Computers and Education 61: 193-208.

13. Lee YH, Hsieh YC, Hsu CN (2011) Adding Innovation Diffusion Theory to the Technology Acceptance Model: Supporting Employees' Intentions to use E-Learning Systems Educational Technology \& Society 14: 124-137.

14. Li C, Irby B (2008) An overview of Online Education: Attractiveness Benefits Challenges Concerns and Recommendations. College Learner Journal 42 449-458.

15. Machemer PL, Crawford P (2007 Learner Perceptions of Active Learning in a Large Cross-Disciplinary Classroom Active Learning in Higher Education 8 : 9-30.

16. Masrom M (2007) Technology Acceptance Model and E-learning. 12th International Conference on Education Sultan Hassanal Bolkiah Institute of Education Universiti Brunei Darussalam.

17. Moreno R, Mayer R (1999) Cognitive principles of multimedia learning: The role of modality and contiguity. Journal of Educational Psychology 91: 358-368.

18. Pan C, Sivo S, Gunter G, Cornell R (2005) Learners Perceived Ease Of Use O An E-Learning Management System: An Exogenous Or Endogenous Variable? J Educational Computing Research 33: 285-307.

19. Park SY (2009) An Analysis of the Technology Acceptance Model in Understanding University Learners' Behavioural Intention to Use e-Learning Educational Technology \& Society 12: 150-162.

20. Punnoose AC (2012) Determinants of Intention to Use eLearning Based on the Technology Acceptance. Model Journal of Information Technology Education 11: 301-337.

21. Radović-Marković M (2010) Advantages and Disadvantages of E-Learning In Comparison To Traditional Forms Of E-Learning Annals of the University of Personae Economics 10: 289-298.

22. Ramirez-Anormaliza, R Sabaté F, Guevara-Viejo F (2015) Evaluating learner acceptance level of e-learning systems 8th International Conference of Education Research and Innovation pp: 2393-2399.

23. Roca JC, Gagne M (2008) Understanding e-learning continuance intention in 
Citation: Saleh ZI (2018) An Empirical Investigation of Learners' Decision to Resume an Online Degree Program . Arts Social Sci J 9: 323. doi: $10.4172 / 2151-6200.1000323$

Page 6 of 6

the workplace: A self-determination theory perspective Computers in Human Behavior 24: 1585-1604.

24. Rym B, Olfa, Mélika BBM (2013) Determinants of E-Learning Acceptance: An Empirical Study in the Tunisian Context American Journal of Industrial and Business Management 3: 307-321.

25. Saadé RG, Kira D (2009) Computer Anxiety in E-Learning: The Effect of Computer Self-Efficacy. Journal of Information Technology Education 8: 177191.

26. Tan M, Shao $P$ (2015) Prediction of learner dropout in e-learning program through the use of machine learning method. International Journal of Emerging Technology 10: 11-17.

27. Tarhini A Hone K, Liu X (2013) Factors Affecting Learners" Acceptance of
e-Learning Environments in Developing Countries: A Structural Equation Modelling Approach International Journal of Information and Education Technology 3: 54-59.

28. Tran KNN (2016) The adoption of blended e-learning technology in Vietnam using a revision of the Technology Acceptance Model. Journal of Information Technology Education: Research 15: 253-282.

29. Weimer M (2002) Learner Centered Teaching: Five Key Changes to Practice Jossey Bass San Francisco.

30. Westen D, Rosenthal R (2003) Quantifying Construct Validity: Two Simple Measures. Journal of Personality and Social Psychology 84: 608-618.

31. Williams C (2007) Research Methods Journal of Business \& Economic Research 5: 65-72. 